\title{
Paternal inheritance of B chromosomes in a parthenogenetic hermaphrodite
}

\author{
LEO W. BEUKEBOOM* MIRIAM SEIF, THOMAS METTENMEYER†, \\ AMY B. PLOWMAN $\$$ \& NICOLAAS K. MICHIELS \\ Arbeitsgruppe Michiels, Max-Planck-Institut für Verhaltensphysiologie, D-82319 Seewiesen, Germany
}

\begin{abstract}
B chromosomes are dispensable elements extra to the standard (A) chromosome complement. They have been described from many sexually reproducing species where they often exploit meiosis to accumulate from one generation to the next. Polycelis nigra is a simultaneously hermaphroditic flatworm that can reproduce either sexually or asexually through pseudogamous parthenogenesis: although individuals mate, the sperm is only used for egg activation but does not contribute genetically to the progeny. B chromosome frequencies were screened in populations from two North Italian lakes and found to vary from 27 to 90 per cent among pseudogamous parthenogenetic individuals. Because these frequencies were unexpectedly high for an asexual population, we looked at the transmission of B chromosomes in field-collected animals and controlled crosses. Animals that did not carry B chromosomes produced offspring with B chromosomes at frequencies of 6-34 per cent. Results from the crosses strongly suggest that B chromosomes are not only inherited maternally, as expected, but also paternally. This is a new mode of inheritance for a $\mathrm{B}$ chromosome. By preventing expulsion from the egg, this B chromosome seems to have acquired biparental transmission in an otherwise asexually reproducing host. We discuss the evolutionary consequences of this observation in more detail.
\end{abstract}

Keywords: asexuality, B chromosome, paternal inheritance, planarian, pseudogamous parthenogenesis, selfish DNA.

\section{Introduction}

Meiosis is a universal process in sexual eukaryotes that seems to have evolved to assure Mendelian segregation of chromosomes (Frank, 1995; Hammerstein, 1995), but appears vulnerable to exploitation by meiotic drive elements (Haig, 1993; Hurst, 1993). Many B chromosomes are examples of such elements. B chromosomes are elements extra to the standard (A) chromosome complement and have been found in many organisms (Jones \& Rees, 1982; Beukeboom, 1994). They are always dispensable, i.e. unnecessary for the survival of the individual, and usually smaller than the other members of the genome. They appear to carry few major active

\footnotetext{
*Correspondence.

†Present address: Experimental Haematology Group, Division of Molecular Medicine, John Curtin School of Medical Research, Australian National University, GPO Box 334, Canberra, ACT 2601, Australia.

$\ddagger$ Present address: Department of Agricultural \& Environmental Science, Ridley Building, University of Newcastle-upon-Tyne, NE1 7RV, U.K.
}

genes and are considered genetically inert owing to their largely heterochromatic state. Despite this, they can have significant phenotypic effects.

Almost all B chromosomes have been found in sexually reproducing organisms (Jones \& Rees, 1982) where they typically exploit existing asymmetries in the processes by which the standard chromosomes are transmitted to the next generation. Examples (reviewed by Jones, 1991) include directed nondisjunction into the generative nucleus in many grasses, mitotic nondisjunction followed by preferential inclusion into the germ line and preferential segregation to the secondary oocyte rather than the first polar body (Hewitt, 1976). B chromosomes in asexually reproducing organisms are expected to have very different characteristics. They cannot 'infect' new genetic lineages because no genetic exchange takes place between individuals.

Pseudogamous parthenogenesis (= gynogenesis) is a mode of asexual reproduction which has been found in over 20 families of animals belonging to six phyla (Kiester et al., 1981; Bell, 1982; Stenseth \& Kirkendall, 1985). In such a system, females need to 
mate with males to receive sperm to start egg development upon fertilization. However, sperm chromosomes are subsequently eliminated from the egg and, as a result, there is no genetic contribution from the father to the progeny. Polycelis nigra is a free-living simultaneously hermaphroditic flatworm (Turbellaria: Tricladida) which occurs in two reproductive modes. Sexual lineages are always diploid and produce haploid gametes by regular meiosis. Pseudogamous parthenogens are always polyploid, usually triploid but sometimes tetraploid, and produce polyploid eggs and sperm through premeiotic doubling followed by a reductional division (Lepori, 1954; Benazzi Lentati, 1970). Although egg fertilization is necessary for initiation of egg development, sperm chromosomes are subsequently eliminated and offspring are essentially maternal clones (Benazzi Lentati, 1970; Benazzi \& Benazzi Lentati, 1976). Cross-fertilization is the rule, but self-fertilization is possible under conditions of prolonged isolation (Benazzi, 1952; Beukeboom, in prep.). After copulation, allosperm can be stored for several months.

We established the reproductive mode and ploidy level from several western European populations of $P$. nigra and found two pseudogamous parthenogenetic populations in which $\mathrm{B}$ chromosomes were very abundant. Using offspring from field-collected animals and controlled crosses, we investigated the inheritance of $\mathrm{B}$ chromosomes, particularly the possibility of paternal transmission in these populations.

\section{Material and methods}

\section{Collections}

Worms were collected from two North Italian lakes in January and July 1994. Lago di Toblino contains a pure pseudogamous parthenogenetic population. In January, worms were collected from only one site in the north (referred to as Toblino-N1), whereas in July, worms were collected from this site (referred to as Toblino-N2), as well as from a second site $\approx 500 \mathrm{~m}$ further south along the west shore (referred to as Toblino-W). Lago di Garlate contains a mixed population of sexuals and pseudogamous parthenogens and samples were taken from the west and east side of the lake (referred to as Garlate-W and -E). Using a squirt bottle, animals were flushed gently from the undersides of stones picked up along the lake shore. The worms were transported to the laboratory in one-litre brown plastic pots and gradually adjusted to water from a large aquarium in the culture room.

\section{Culture}

Worms were kept individually in $200 \mathrm{~mL}$ brown plastic pots which have mesh-sealed openings on two sides to allow water exchange. Pots were placed in water-filled white containers at $18-22^{\circ} \mathrm{C}$ at a constant day/night cycle of $16 \mathrm{~L}: 8 \mathrm{D}$. Animals were fed once or twice per week with red mosquito larvae or ground beef liver. All remaining food was carefully removed and the water replaced within $24 \mathrm{~h}$ after feeding.

Animals collected from Lago di Toblino were immediately isolated in the laboratory and checked every day. Cocoons were carefully removed with a plastic pipette and transferred to plastic Petri dishes (diameter $6 \mathrm{~cm}$ ) half-filled with water. Cocoons were inspected daily for hatching. Newly hatched young were transferred into ice-cube containers and maintained as described for adults. Cocoons which had not hatched within one month were opened with a needle to check for unhatched young. After production of several cocoons over a period of a few months, adults and offspring were karyotyped. An animal that produced cocoons from which hatchlings emerged is referred to as the 'mother' of the offspring. Because these worms had mated in the field and can store sperm for at least 4 months (personal observation), the 'father' is unknown in these experiments.

Animals collected from Lago di Garlate 'west' were split into two groups. Group 1 was set up immediately for cocoon production similar to the Lago di Toblino samples. Animals in Group 2 were first isolated for 3 months and subsequently kept in randomly assembled pairs for 6 weeks. The purpose of this experiment was to see whether B chromosome transmission changed because worms in Group 2 started to use sperm from their captive mate, rather than sperm stored from previous matings in the wild. Because cocoons were collected while both (hermaphroditic) individuals remained together during this period, the actual parent of each individual cocoon could not be determined. Animals from Garlate-E were not maintained for cocoon production, but karyotyped immediately upon arrival in the laboratory.

\section{Karyology}

Chromosome numbers were established according to a modified protocol of Redi et al. (1982). A regener- 
ating tail section (about $1 / 5$ of an adult specimen) or an entire young (1-3 $\mathrm{mm}$ in size) was placed in a 0.15 per cent colchicine solution in container water. After 4-7 h at room temperature, tissue was hypotonized in distilled water for $15 \mathrm{~min}$ and then fixed in ice-cold Carnoy's solution ( 3 parts ethanol, 1 part acetic acid) and stored at $-20^{\circ} \mathrm{C}$. Fixed samples were placed on a microscope slide in a drop of 45 per cent acetic acid for $20 \mathrm{~min}$, then chopped into pieces and squashed under a cover glass. Chromosomes were counted under phase contrast at a magnification of $1000 \times$ on an Olympus BHS or BH2-RFCA microscope. At least three, but usually about 10 cells, were scored to determine chromosome numbers reliably.

\section{Statistics}

The analysis of $\mathrm{B}$ chromosome transmission rates was performed with the one-sample Wilcoxon test using the BMDP statistical package. B chromosome frequency changes were tested with the chi-square test using STATXACT-TURBO.

\section{Results}

\section{Chromosome numbers}

Polycelis nigra has a haploid complement of eight chromosomes. In Lago di Toblino, only polyploid pseudogamous parthenogens were found and most of them were triploid, but some were tetraploid (Table 1). Two types of supernumerary chromosomes were found (Fig. 1), typical B chromosomes and extra standard-like chromosomes. B chromosomes were smaller than the smallest A chromosome and predominantly ( 98 per cent) metacentric. At this point, we do not know whether the extra standard-like chromosomes are polysomics of an A chromosome, or $\mathrm{B}$ chromosomes that resemble $\mathrm{A}$ chromosomes. They fall beyond the scope of this paper.

Frequencies of individuals with $\mathrm{B}$ chromosomes were high, ranging from 38 per cent (site N2) to 90 per cent (site $\mathrm{W}$ ). The maximum number of $\mathrm{B}$ chromosomes per individual was three (Table 1). At sites N1 and N2 animals without Bs were most abundant, but at site $\mathrm{W}$ animals with $1 \mathrm{~B}$ were more common. B chromosomes were mitotically stable, i.e. all cells within an individual contained the same number.

Lago di Garlate contained a mixed population of sexuals and pseudogamous parthenogens. At Garlate-W, 9 per cent of individuals were diploid, 90 per cent triploid and 1 per cent tetraploid, whereas only triploids were found at Garlate-E. B chromosomes were only found in polyploids, at frequencies of 27 per cent and 33 per cent, respectively. They were morphologically indistinguishable from the B chromosomes found in Lago di Toblino. However, numbers within an individual ranged from zero to two per cell indicating that they were mitotically unstable. An individual was scored as having a B chromosome if a B was found in at least one cell, but no distinction was made between one or two Bs (Table 1). Mitotically unstable extra standard-like chromosomes were also found in some individuals.

\section{Field-collected animals}

Karyotypes of field-collected animals ('mothers') and their offspring produced in the laboratory are listed in Table 2 for all Toblino samples. The data are consistent for all three groups and show that (1) offspring from mothers without $\mathrm{B}$ chromosomes usually had no Bs but sometimes one, and (2) mothers with $\mathrm{B}$ chromosomes typically produced offspring with the same number of Bs, but sometimes a B was 'lost' or 'gained'. The gain of one B is most remarkable in those cases where the mothers

Table 1 Frequencies of ploidy levels (x) and B chromosomes in Polycelis nigra from sample sites in two North Italian lakes

\begin{tabular}{|c|c|c|c|c|c|c|c|c|c|}
\hline \multirow[b]{2}{*}{ Locality } & \multirow[b]{2}{*}{ Number } & \multicolumn{3}{|c|}{ Proportion individuals with } & \multicolumn{4}{|c|}{ Proportion individuals with } & \multirow[b]{2}{*}{$\geq 1 \mathrm{~B}$} \\
\hline & & $2 \mathrm{x}$ & $3 x$ & $4 \mathrm{x}$ & 0B & $1 \mathrm{~B}$ & $2 B$ & $3 \mathrm{~B}$ & \\
\hline Lago di Toblino-N1 & 155 & 0 & 1.00 & 0 & 0.51 & 0.44 & 0.04 & 0.01 & \\
\hline Lago di Toblino-N2 & 110 & 0 & 0.97 & 0.03 & 0.62 & 0.31 & 0.06 & 0.01 & \\
\hline Lago di Toblino-W & 154 & 0 & 0.99 & 0.01 & 0.10 & 0.62 & 0.26 & 0.02 & \\
\hline Lago di Garlate-W & 117 & 0.09 & 0.90 & 0.01 & 0.73 & & & & $0.27 \dagger$ \\
\hline Lago di Garlate-E & 30 & 0 & 1.00 & 0 & 0.67 & & & & 0.33 \\
\hline
\end{tabular}

In Lago di Garlate the exact number of B chromosomes could not be determined because they were mitotically unstable. $\uparrow \mathrm{B}$ chromosomes only present in polyploids. 


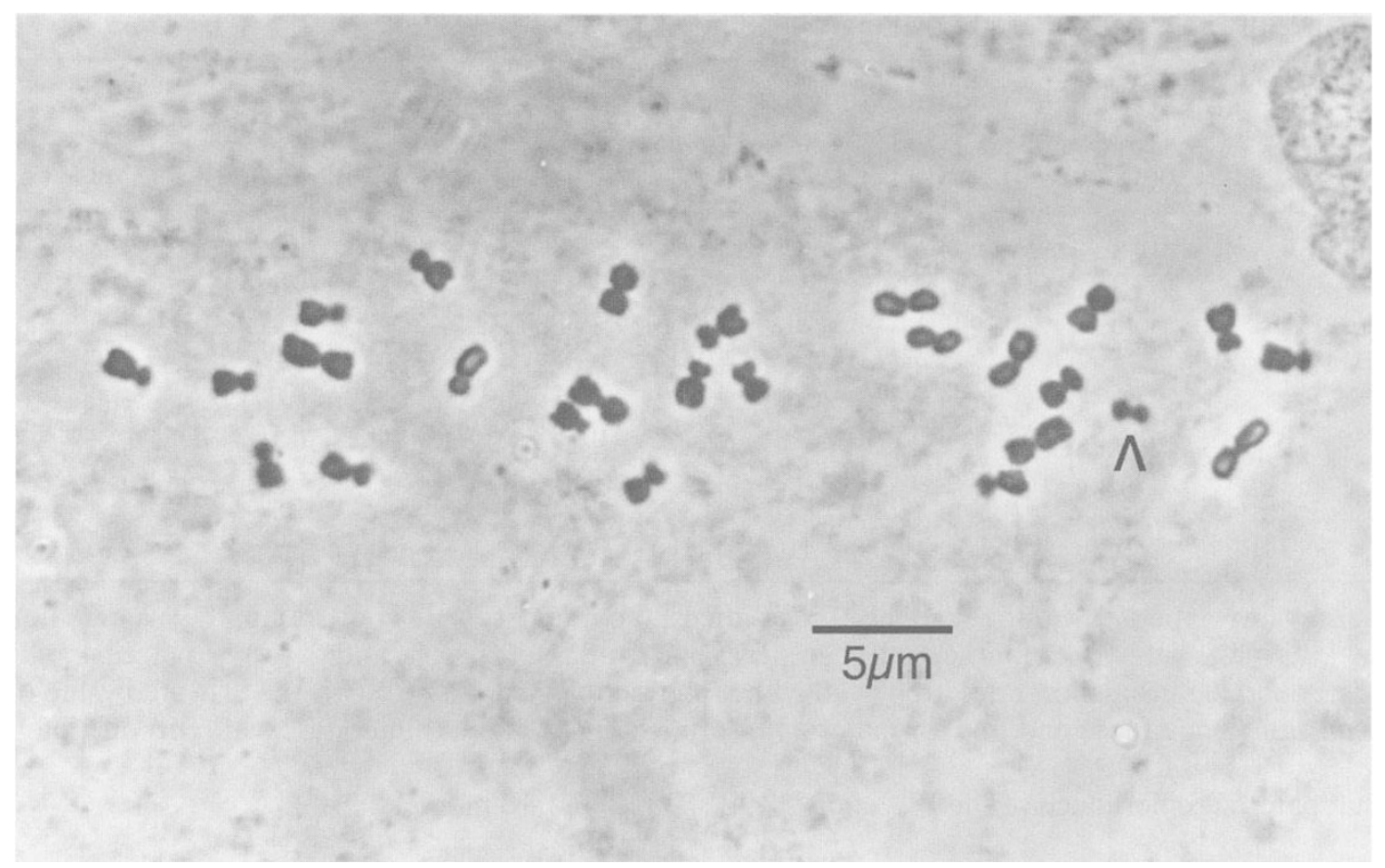

Fig. 1 Karyotype of a triploid pseudogamous parthenogenetic Polycelis nigra from Lago di Toblino showing $2 n=3 \mathrm{x}=24$ standard (A) chromosomes, one indistinguishable extra standard-like chromosome and one B chromosome (arrow).

had no B. Assuming a paternal origin, this represents a paternal transmission rate that is significantly higher than the expected zero transmission under asexual reproduction. Maternal transmission rates are expected to be one if no loss occurs during oogenesis. In Table 2, maternal transmission rates have been corrected for the average paternal transmission rate. This assumes that paternal transmission in mothers without B chromosomes is equal to mothers that carry B chromosomes. Resulting maternal transmission rates are significantly lower than the expected rate of one.

\section{Controlled crosses}

Offspring from Garlate-W Group 1 that emerged from cocoons before pairing showed the same pattern as the Lago di Toblino samples. Most offspring had karyotypes identical to their mother, but 34 per cent of the offspring from mothers without Bs carried one B and 22 per cent of the offspring from mothers with one $\mathrm{B}$ carried no $\mathrm{B}$ (Table 3). After pairing (Group 2), a total of 24 pairs in which neither partner carried a B chromosome produced at least one offspring. Four pairs in which one partner carried one B chromosome were discarded because the actual mothers could not be determined. The 24 pairs without $\mathrm{B}$ chromosomes produced a total of 46 offspring of which 9 per cent carried one B and 91 per cent zero Bs. The frequency of $1 \mathrm{~B}$ offspring from $0 \mathrm{~B}$ mothers after captive pairing was significantly lower than before pairing (42:4 in Group 2 vs. $37: 19$ in Group I, $\left.\chi_{1}^{2}=9.21, P<0.005\right)($ Table 3$)$.

\section{Stability of B chromosome frequencies}

Frequencies of B chromosomes among fieldcollected animals, mothers and their progeny are compared in Table 4. The group 'mothers' forms a subgroup of the group 'field collection'. The average number of B chromosomes in samples Toblino-N1 (from January, 1994) and N2 (from July, 1994) was $\approx 0.5$ per individual. In general, B frequencies did not change in one generation at these sites. An exception is sample N2 in which progeny had fewer Bs than the field-collected animals (chi-square test, $P=0.019$ ), but not their mothers. This most likely results from the fact that no mothers with more than one $\mathrm{B}$ were selected for transmission analysis, whereas such animals were present in the field sample. In Toblino-W worms carried on average 1.2 
Table 2 Inheritance of B chromosomes in Lago di Toblino populations of Polycelis nigra

\begin{tabular}{|c|c|c|c|c|c|c|c|c|c|c|c|c|}
\hline \multirow[b]{2}{*}{ Sample } & \multirow{2}{*}{$\begin{array}{l}\text { No. of Bs } \\
\text { in mother }\end{array}$} & \multirow{2}{*}{$\begin{array}{l}\text { No. of } \\
\text { mothers }\end{array}$} & \multicolumn{5}{|c|}{ Number of offspring with } & \multirow{2}{*}{$\begin{array}{c}\bar{x}_{\mathrm{B}} \\
\text { progeny }\end{array}$} & \multirow{2}{*}{$\begin{array}{l}\text { Expected } \\
k_{\mathrm{B}} \text { father }\end{array}$} & \multirow{2}{*}{$\begin{array}{l}\text { Observed } \\
k_{\mathrm{B}} \text { father }\end{array}$} & \multirow{2}{*}{$\begin{array}{l}\text { Expected } \\
k_{\mathrm{B}} \text { mother }\end{array}$} & \multirow{2}{*}{$\begin{array}{l}\text { Observed } \\
k_{\mathrm{B}} \text { mother }\end{array}$} \\
\hline & & & $0 \mathrm{~B}$ & $1 \mathrm{~B}$ & $2 \mathrm{~B}$ & $3 \mathrm{~B}$ & Total & & & & & \\
\hline \multirow{2}{*}{ Toblino-N1 } & 1 & 8 & 6 & 28 & 3 & 0 & 37 & 0.92 & - & $0.18 \dagger$ & 1 & $0.74^{*}$ \\
\hline & 2 & 1 & 0 & 0 & 3 & 0 & 3 & 2.00 & - & $0.18 \dagger$ & 1 & 0.82 \\
\hline \multirow[t]{4}{*}{ Toblino-W } & 0 & 9 & 35 & 7 & 0 & 0 & 42 & 0.16 & 0 & 0.16 & - & - \\
\hline & 1 & 50 & 4 & 182 & 28 & 0 & 214 & 1.11 & - & $0.16 \dagger$ & 1 & $0.95^{*}$ \\
\hline & 2 & 23 & 0 & 4 & 95 & 9 & 108 & 2.04 & - & $0.16 \dagger$ & 1 & $0.86 * *$ \\
\hline & 3 & 1 & 0 & 0 & 0 & 1 & 1 & 3.00 & - & $0.16 \dagger$ & 1 & 0.84 \\
\hline
\end{tabular}

For each maternal karyotype is given the number of individuals, the number of Bs in offspring, the average number of Bs in the progeny $\left(\bar{x}_{\mathrm{B}}\right.$, first averaged per mother and then per group) and the expected and observed paternal and maternal transmission rates $\left(k_{\mathrm{B}}\right)$. Transmission rates are tested with a one-sample Wilcoxon test vs. the expected value of zero for paternal transmission (one-tailed) and one for maternal transmission (two-tailed) under asexual reproduction $(*=P<0.05, * *=P<0.01)$.

† Assuming that paternal inheritance of the $\mathrm{B}$ is equal in $0 \mathrm{~B}, 1 \mathrm{~B}, 2 \mathrm{~B}$ and $3 \mathrm{~B}$ mothers.

Table 3 Inheritance of B chromosomes in the Lago di Garlate-W population of Polycelis nigra

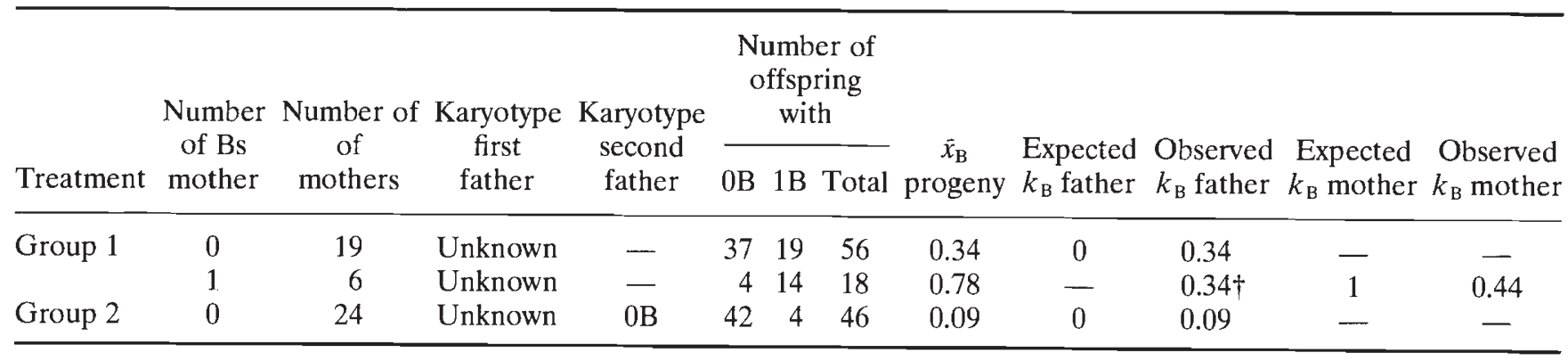

In group 1, animals were set up for cocoon production immediately after collection, whereas individuals from group 2 were first kept in isolation for three months and subsequently randomly paired. For each maternal karyotype is given the number of individuals, the number of Bs in offspring, the average number of Bs in the progeny $\left(\bar{x}_{\mathrm{B}}\right)$ and the observed and expected paternal and maternal transmission rates $\left(k_{\mathrm{B}}\right)$. In Group 2 only pairs of which both partners had no B chromosome are indicated. Karyotypes of first fathers could not be determined because animals had mated in the field and store sperm. The frequency of $1 \mathrm{~B}$ offspring from $0 \mathrm{~B}$ mothers is significantly lower in Group 2 than in Group 1 $\left(\chi_{1}^{2}=9.21, P<0.005\right)$, indicating partial use of sperm from second mates.

+ Assuming that paternal inheritance of the $\mathrm{B}$ is equal in $0 \mathrm{~B}$ and $1 \mathrm{~B}$ mothers.

$\mathrm{B}$ chromosomes and this number did not change in one generation. In Garlate-W, progeny carried more Bs than the field-collected animals $(P=0.014)$ and mothers $(P=0.069)$.

\section{Discussion}

While screening pseudogamous parthenogenetic populations of the flatworm $P$. nigra in two lakes, we found that frequencies of $\mathrm{B}$ chromosomes were very high (27 per cent to 90 per cent) with up to three per individual. In general, $\mathrm{B}$ chromosome frequen- cies did not change within a single generation in Lago di Toblino samples. In Lago di Garlate offspring had more Bs than their parents, indicating a net increase in the population frequency. However, the frequency of B chromosomes in parents could have been underestimated because of their mitotic instability in this population. It is known that B chromosomes can be lost from somatic tissue but still be present in germ lines resulting in a higher number of $\mathrm{B}$ chromosomes in the germ line than that observed in the somatic cells (Jones \& Rees, 1982). This phenomenon is typical 
Table 4 Comparison of B chromosome frequencies in parents and offspring in Polycelis nigra from sample sites in two North Italian lakes

\begin{tabular}{llrrrrrrc}
\hline Sample & Individuals & 0B & 1B & 2B & 3B & Total & $\bar{x}_{\mathrm{B}}$ & Chi-square test \\
\hline Toblino-N1 & Field collection & 79 & 69 & 6 & 1 & 155 & 0.542 & $\chi_{3}^{2}=2.314, P=0.509$ \\
& Progeny & 61 & 40 & 6 & - & 107 & 0.486 & $\chi_{2}^{2}=0.139, P=0.933$ \\
& Mothers & 14 & 8 & 1 & - & 23 & 0.435 & \\
Toblino-N2 & Field collection & 68 & 34 & 7 & 1 & 110 & 0.464 & $\chi_{3}^{2}=9.952, P=0.019$ \\
& Progeny & 90 & 40 & - & - & 130 & 0.308 & $\chi_{1}^{2}=1.598, P=0.206$ \\
& Mothers & 25 & 6 & - & - & 31 & 0.194 & \\
Toblino-W & Field collection & 16 & 95 & 40 & 3 & 154 & 1.156 & $\chi_{3}^{2}=3.853, P=0.278$ \\
& Progeny & 39 & 193 & 123 & 10 & 365 & 1.285 & $\chi_{3}^{2}=2.071, P=0.558$ \\
& Mothers & 9 & 50 & 23 & 1 & 83 & 1.193 & \\
Garlate-W & Field collection & 85 & 32 & - & - & 117 & 0.27 & $\chi_{1}^{2}=6.004, P=0.014$ \\
& Progeny & 41 & 33 & - & - & 74 & 0.45 & $\chi_{1}^{2}=3.320, P=0.069$ \\
& Mothers & 19 & 6 & - & - & 25 & 0.24 & \\
\hline
\end{tabular}

The group 'mothers' forms a subset of the group 'field collection' $\bar{x}_{\mathrm{B}}=$ average number of B chromosomes in progeny. A significant Chi-square value indicates a net change in $\mathrm{B}$ chromosome frequency in a single generation.

for mitotically unstable B chromosomes in grasshoppers (Rothfels, 1950; Nur, 1969; Kayano, 1971; Pardo et al., 1994) and has also been reported for Polycelis tenuis by Melander (1950).

In the laboratory, many individuals were found to produce offspring with karyotypes different from their own. Loss of a B is not surprising because B chromosomes are known to be lost occasionally during meiosis (Jones \& Rees, 1982). However, because these worms are believed to reproduce asexually, the finding that mothers without $\mathrm{B}$ chromosomes often produced offspring with one B is most remarkable. There are three possible explanations for these results. First, B chromosomes could originate 'de novo' each generation. Actual data on the rate of origin of new chromosome variants are very scarce, which by itself implies that it is probably a rare event. For example, Parker \& Wilby (1989) found one new variant among every 50 offspring in the plant Rumex acetosa and López-León et al. (1993), in a detailed study of B chromosomes in the grasshopper Eyprepocnemis plorans, found new B variants with a frequency of $0.05-0.21$ per cent. In general, reported frequencies of new chromosomal variants in a variety of organisms range from 1 in 1000 to 1 in 10000 per gamete per generation (Lande, 1979; Hook, 1984; Hook et al., 1984; Nachman \& Searle, 1995). We found B chromosomes to occur in offspring of $0 \mathrm{~B}$ mothers with frequencies up to 34 per cent. Such frequencies have never been reported and a 'de novo' origin therefore seems very unlikely.

A second possible explanation is mitotic instability of the B chromosomes. They may be overlooked in mothers, but transmitted to offspring. We used somatic tissue from adults, i.e. regenerated blastemas, and whole juvenile animals to determine karyotypes. To explain our results, one would have to make the unlikely assumption that the Bs are absent from the somatic cells from mothers (completely mitotically unstable), but present in somatic cells from young (mitotically stable). This is in contrast with the karyological data which show that B chromosomes are, at least in Lago di Toblino, mitotically stable in both adults and young. In Garlate-W, there is some mitotic instability which may have led to a slight overestimate of the frequency of paternal inheritance in this population. However, this cannot be the full explanation for our results, because the data indicate that even the $\mathrm{B}$ chromosomes in Garlate are at least partially mitotically stable and can be detected when enough cells are looked at.

The third, both most likely and most interesting, explanation is paternal inheritance of the B chromosomes. This implies that a B chromosome enters the egg via the sperm but is subsequently not eliminated in contrast to the paternal autosomes. Unfortunately, we could not determine the karyotype of the fathers because worms had mated in the field and store sperm for several months. However, results from the two experimental Garlate-W groups are consistent only with the paternal inheritance explanation. The frequency of $+B$ offspring from $0 B$ mothers was significantly reduced after 3 months of isolation and subsequent pairing to other $0 \mathrm{~B}$ individ- 
uals. This is not predicted by the 'de novo origin' hypothesis. It can only be explained by a reduced frequency of paternal inheritance of Bs resulting from an increased use of $0 \mathrm{~B}$ sperm from the experimental partners. These results do not exclude a low rate of 'de novo' origin, because some $0 \mathrm{~B}$ mothers still produced $+\mathrm{B}$ offspring. However, a likely alternative explanation is that some mothers were still using stored $+B$ sperm from field matings. It is known from other experiments that $P$. nigra can store sperm for at least 4 months (unpublished results).

It is worth estimating the proportion of Bs in the field that is paternally transmitted. An index for paternal transmission can be estimated as the quotient between 'mean number of $\mathrm{Bs}$ in the offspring of $0 \mathrm{~B}$ mothers' and 'mean number of Bs per individual in the field population'. Values are $0.33(0.18 / 0.542)$ for Toblino-N1, $0.15(0.07 / 0.469)$ for Toblino-N2, $0.14(0.16 / 1.156)$ for Toblino-W and $1.26(0.34 / 0.27)$ for Garlate-W. The estimate for this last population could be biased because of mitotic instability of the Bs. The values indicate that paternal transmission rates differ among populations. This could be the outcome of local differences in interactions between $\mathrm{B}$ chromosomes and their host's genome.

It is clear that exact rates of maternal and paternal inheritance in $+B$ animals cannot yet be determined because the genotypes of the fathers were not known. At present, there are still two possible explanations for offspring having one $\mathrm{B}$ more than their mother when she has a B herself. The extra B could be of maternal origin and the result of nondisjunction during oogenesis. Alternatively, it could have come from the father and escaped elimination from the egg. Because frequencies at which $B s$ are gained in offspring from 1 and $2 \mathrm{~B}$ mothers are similar to those in $\mathrm{OB}$ mothers, the latter explanation of origin seems more likely. Because some offspring had fewer Bs than their mother (up to 11 per cent in Toblino samples and 22 per cent in Garlate), maternal transmission rates were generally lower than one when they were corrected for paternal transmission rates. This indicates occasional loss of the $\mathrm{B}$ during oogenesis. It should, however, be noted that oogenesis and spermatogenesis are aberrant in these polyploids. First there is a premeiotic doubling without cell division followed by a reduction division resulting in polyploid sperm (Lepori, 1954; Benazzi Lentati, 1970). Cytological analysis (in collaboration with L. Pijnacker, University of Groningen) indicates that the B chromosomes do not differ from the standard chromosomes in this respect.
Escaping expulsion in a pseudogamous parthenogenetic system is a mode of $\mathrm{B}$ chromosome transmission that has not been described previously. Interestingly, this novel B chromosome inheritance mechanism mostly resembles that of the Paternal Sex Ratio (PSR) chromosome of the wasp Nasonia vitripennis (Werren, 1991; Beukeboom \& Werren, 1993a). The PSR B chromosome is inherited only paternally, but actively destroys the sperm chromosomes after fertilization of an egg, whereas it survives itself. In $P$. nigra paternal chromosomes are eliminated from the fertilized egg because of pseudogamous parthenogenesis. There appear to be two modes by which this occurs, either expulsion of the sperm chromosomes with a cytoplasmic bud or degeneration of the sperm nucleus in the egg cytoplasm (Benazzi Lentati, 1970). Although the phenomenon of surviving paternal chromosome elimination from the egg is the same for the Polycelis and Nasonia B chromosomes, the genetic mechanism may be very different and remains unknown (Beukeboom \& Werren, 1993b).

Recently, Schartl et al. (1995) reported a similar case of paternal inheritance from the gynogenetic fish Poecilia formosa, the Amazon molly. This is an all-female species that mates with males from a related sexual species. A centromeric fragment was found in $P$. formosa offspring that appears to contain a gene for black pigment which is normally only present in the species that acted as father. Although they termed their supernumerary element a microchromosome, it can be considered a B. The transmission dynamics of this system are, however, different from $P$. nigra in that $P$. formosa is an all-female species relying on males from a related sexual species for sperm. Polycelis nigra is a simultaneous hermaphrodite in which each individual has a functional male and female reproductive system. As a result, B chromosomes in $P$. formosa can only be transmitted unidirectionally from the male species to $P$. formosa, whereas in $P$. nigra they can be transmitted from each individual to the offspring of any other individual, even within an all-asexual population, and therefore 'jump' between asexual lineages. This could explain why frequencies of B chromosomes are much higher in populations of $P$. nigra than $P$. formosa. What both systems show is that biparental inheritance is sometimes possible under pseudogamous parthenogenesis. This infringes upon the view that pseudogamous parthenogenesis is a clonal mode of reproduction

Many B chromosomes can be considered as 'selfish' DNA (Doolittle \& Sapienza, 1980; Orgel \& Crick, 1980) or genomic parasites (Werren et al., 
1988; Bell \& Burt, 1990; Shaw \& Hewitt, 1990; Beukeboom, 1994) because they enhance their own transmission relative to the host genome. Even though we do not yet know whether B chromosomes in P. nigra affect their host's fitness, their ability to gain a transmission advantage over the host's genome can be considered as parasitic. An interesting question is whether B chromosomes in pseudogamous parthenogens have been selected for surviving expulsion from the egg. Such selection on the B could never take place in $P$. formosa because the $\mathrm{B}$ never comes back to the paternal species. In contrast, a B chromosome that can be inherited through both the female and male line in $P$. nigra would have a transmission advantage over a $B$ that can only pass through the female line, and hence be favoured by selection.

In conclusion, the ability to be inherited paternally can explain the high frequencies of B chromosomes that are observed in some pseudogamous parthenogenetic populations of $P$. nigra. It also illustrates that the mode of inheritance (uniparental vs. biparental) can be different for chromosomes within an individual.

\section{Acknowledgements}

We appreciate comments from Juan Pedro M. Camacho on statistical procedures and the presentation of results. We thank Tim Sharbel and Angel Martín Alganza for comments on earlier versions of the manuscript. A.B.P was supported by a stipend from the Max-Planck-Gesellschaft.

\section{References}

BELL, G. 1982. The Masterpiece of Nature. Croom Helm, London.

BELL, G. AND BURT, A. 1990. B chromosomes: germ-line parasites which induce changes in host recombination. Parasitology, 100, S19-S26.

BENAZZI, M. 1952. Sulla possibilità di reproduzione sessuata senza accoppiamento in Tricladi di acqua dolce. Atti Soc. Tosc. Sc. Nat. Ser. B, 59, 107-110.

BENAZZi, M. AND BENAZZi leNTAti, G. 1976. Platyhelminthes. In: John, B. (ed.) Animal Cytogenetics, vol 1, pp. 1-77. Gebrüder Borntraeger, Berlin-Stuttgart.

BENAZZI LENTATI, G. 1970. Gametogenesis and egg fertilization in planarians. Int. Rev. Cytology, 27, 101-179.

BEUKEBOOM, L. w. 1994. Bewildering Bs: an impression of the 1st B-chromosome Conference. Heredity, 73, 328-336.

BEUKEBOOM, L. W. AND Werren, J. H. 1993a. Transmission and expression of the parasitic paternal sex ratio (PSR) chromosome. Heredity, 70, 437-443.
BeUKEboOm, L. W. AND Werren, J. H. 1993b. Deletion analysis of the selfish $B$ chromosome, Paternal Sex Ratio $(P S R)$, in the parasitic wasp Nasonia vitripennis. Genetics, 133, 637-648.

DOOLITTLE, W. F. AND SAPIENZA, c. 1980. Selfish genes, the phenotype paradigm and genome evolution. Nature, 284, 601-603.

FRANK, S. A. 1995. Mutual policing and repression of competition in the evolution of cooperative groups. Nature, 377, 520-522.

HAIG, D. 1993. Alternatives to meiosis: the unusual genetics of red algae, microsporidia, and others. $J$. Theor. Biol., 163, 15-31.

HAMMERSTEIN, P. 1995. A twofold tragedy unfolds. Nature, $377,478$.

HEwITT, G. M. 1976. Meiotic drive for B chromosomes in the primary oocytes of Myrmeleotettix maculatus (Orthoptera: Acrididae). Chromosoma, 56, 381-391.

HOOK, Е. B. 1984. Parental age and unbalanced Robertsonian translocations associated with Down syndrome and Patau syndrome: comparison with maternal and paternal age effects for $47,+21$ and 47, +13. Ann. hum. Genet., 48, 313-325.

HOOK, E. B., CROSS, P. K. AND REGAL, R. R. 1984. The frequency of $47,+21,47,+18$ and $47,+13$ at the uppermost extremes of maternal ages: results on 56,094 fetuses studied prenatally and comparisons with data on livebirths. Hum. Gen., 68, 211-220.

HURST, L. D. 1993. Drunken walk of the diploid. Nature, 365, 206-207.

JONES, R. N. 1991. B-chromosome drive. Am. Nat., 137, $430-442$.

JONES, R. N. AND REES, H. 1982. B Chromosomes. Academic Press, London.

KAYANO, H. 1971. Accumulation of B chromosomes in the germ-line of Locusta migratoria. Heredity, 27, 119-1123.

KIESTER, A. R., NAGYLAKI, T. AND SHAFFER, B. 1981. Population dynamics of species with gynogenetic sibling species. Theor. Pop. Biol., 19, 358-369.

LANDE, R. 1979. Effective deme sizes during long-term evolution estimated from rates of chromosomal rearrangement. Evolution, 33, 234-251.

LEPORI, N. G. 1954. Nuova mutazione genomica in Polycelis nigra Ehrenberg. Caryologia, 6, 90-102.

LOPÉZ-LEÓN, M. D., CABRERO, J., PARDO, M. C., VISERAS, E., CAMACHO, J. P. M. AND SANTOS, J. L. 1993. Generating high variability of B chromosomes in Eyprepocnemis plorans (grasshopper). Heredity, 71, 352-362.

MELANDER, Y. 1950. Accessory chromosomes in animals, especially in Polycelis tenuis. Hereditas, 36, 19-38.

NACHMAN, M. W. AND SEARLE, J. B. 1995. Why is the house mouse karyotype so variable? Trends Ecol. Evol., 10, 397-401.

NUR, U. 1969. Mitotic instability leading to an accumulation of B-chromosomes in grasshoppers. Chromosoma, 27, 1-19.

ORGEL, L. E. AND CRICK, F. H. C. 1980. Selfish DNA: the ultimate parasite. Nature, 284, 604-607. 
PARDO, M. C., LOPÉZ-LEÓN, M. D., CABRERO, J. AND CAMACHO, J. P. M. 1994. Transmission analysis of mitotically unstable B chromosomes in Locusta migratoria. Genome, 37, 1027-1034.

PARKER, J. S. AND WILBY, A. s. 1989. Extreme chromosomal heterogeneity in a small-island population of Rumex acetosa. Heredity, 62, 133-140.

REDI, C. A., GARAGNA, S. AND PELliCCIARJ, C. 1982. Chromosome preparation from planarian blastemas: A procedure suitable for cytogenetic and cytochemical studies. Stain Technol., 57, 190-192.

ROTHFELS, K. H. 1950. Chromosome complement, polyploidy and supernumeraries in Neopodismopsis abdominalis. Chromosomes Today, 1, 28-30.

SCHARTL, M., NANDA, 1., SCHLUPP, 1., WILDE, B., EPPLEN, J.
T., SCHMID, M. AND PARZEFALL, J. 1995. Incorporation of subgenomic amounts of DNA as compensation for mutational load in a gynogenetic fish. Nature, 373, 68-71.

SHAW, M. W. AND HEWITT, G. M. 1990. B chromosomes, selfish DNA and theoretical models: where next? In: Futuyma, D. and Antonovics, J. (eds) Oxford Surveys in Evolutionary Biology, vol. 7, pp. 197-223. Oxford University Press, Oxford.

STENSETH, N. C. AND KIRKENDALL, L. R. 1985. On the evolution of pseudogamy. Evolution, 39, 294-307.

werren, J. H. 1991. The Paternal-Sex-Ratio chromosome of Nasonia. Am. Nat., 137, 392-402.

WERREN, J. H., NUR, U. AND WU, C.-1. 1988. Selfish genetic elements. Trends Ecol. Evol., 3, 297-302. 